\title{
Ecological Land-Use Variety and Security Pattern Construction: A Case Study from Anqing, China
}

\author{
Jiulin Li, Shanshan Li, Jiangang Xu \\ School of Architecture and Urban Planning, Nanjing University, Gulou Campus, Nanjing, China \\ Email: 1jiu190@163.com, 781191178@qq.com,xjg129@sina.com
}

How to cite this paper: Li, J.L., Li, S.S. and Xu, J.G. (2019) Ecological Land-Use Variety and Security Pattern Construction: A Case Study from Anqing, China. Journal of Computer and Communications, 7, 72-84. https://doi.org/10.4236/jcc.2019.77008

Received: April 3, 2019

Accepted: July 7, 2019

Published: July 10, 2019

\begin{abstract}
Ecological security is an overall reflection of the ecological integrity and health level of natural semi-natural ecosystems. The study obtained quantitative results of ecological land-use variety by using spatial transfer matrix, based on status maps of Anqing City in 2005 and 2017. We combined the superposition analysis of ecological sensitivity with ecological disturbance evaluation to judge the strategic nodes and corridors of core protection type, including maintenance promotion type and potential supplementary type in the study area. In addition, we introduced the model of minimum cumulative resistance to construct the ecological security pattern, superimposing with the results of ecological land use. According to the trend of change over the past decade, the study has the great significance to the ecological security pattern so that we can effectively guide to take management strategy for security landscape.
\end{abstract}

\section{Keywords}

Minimum Cumulative Resistance, Ecological Security, Transfer Matrix

\section{Background}

Urbanization has become an inevitable trend toward ecosystem in the 21st century. A highly dense growing urban population, an increasing consumption demand, and the increasing ability to utilize natural resources are depleting land resources. To satisfy city productivity, the transformation from ecological land (e.g., arable land, forest, grassland, wetlands) to constructed land (e.g., residential, commercial, industrial land) is more intense, especially in low- and middle-income countries in Asia, Africa, and Latin America facing severe urban 
population pressure before industrialization. As we all know, ecological land-use takes a large part in coordinating environment and ecological conservation to maintain regional ecological balance and sustainable development. Despite Land classification system do not regard ecological land as an independent type at home and abroad, it remains several scholars to study and classify it from different aspects. Then the ecological land use will be evaluated toward different areas [1].

Ecological security refers to the overall reflection that mainly provides ecological integrity and health level of natural semi-natural ecosystems proposed by the book, Building a Sustainable Society, originated in the early 1980s. From then on, the topic was gradually paid more attention with the degeneration of environment variety. Some scholars put forward the concept (ecological security pattern), based on ecological security from the perspective of landscape ecology in 1990s. Therefore, the pattern refers to a multi-level, continuous and complete ecosystem space network, provided good ecological services for human survival and development, that is critical to the maintenance and health control in regional ecological processes [2]. With the realization of the limitations of ecological security research, domestic study gradually developed a research on ecological security pattern at a late starting [3]. However, studies on the pattern generally just focus on static points, including landscape pattern optimization, land use structure optimization, ecosystem service value, ecosystem carrying capacity, ecological footprint assessment, sustainable use of land resources and so on. Based on it, the methods can be categorized as three types, including index optimization model, suitability, sensitivity evaluation model and ecological process model [4]. From this application study, the MCRM is innovative regarded as one of the best tools in spatial temporal analysis of ecological security pattern, which can apply on management strategy of ecological security pattern by spatial and temporal analysis of ecological security pattern and superposition of ecological land-use variety.

\section{Materials and Methods}

\subsection{Study Area}

Anqing, China, is located in the southwest of Anhui Province and north of the Yangzi River, including Anqing downtown area, Tongcheng, Huaining, Zongyang, Qianshan, Taihu, Susong, Yuexi 7 throughout city. The land area of $13,539 \mathrm{~km}^{2}$ and a population 4.61 million people, where the scale is the same as Lebanon. Dabie Mountain in the northwest has a high altitude with high vegetation coverage. The southeastern part of the country has a low and flat topography. It is the main area of human activities with relative low vegetation coverage and dense distribution of rivers and lakes. The Yangtze River flows through 243 $\mathrm{km}$ in Anqing, and the lakes, such as Huang Lake, Bo Lake, Longgan Lake, are large. So Anqing is the typical landscape city with the landform of low mountains, hills, plains from former aspects (Figure 1) [5]. Therefore, it is positive for 
the ecological security and land-use of such landscape-type cities to analyze spatial and temporal changes in the ecological security pattern for two years, integrating ecological unique resources to landscape cities.

\subsection{Materials and Data Sources}

We used 2005 and 2017 land-use classification map as the remote vector data for this study. We selected the data from Anqing City Land Use Master Plan, Anqing City Water Resources Comprehensive Plan, Anqing City Geological Disaster Prevention Plan and then applied it on the platform of ArcGIS followed by calibration and vectorization. Besides, we introduced DEM elevation data, which is a $30 \mathrm{~m}$ resolution grid, derived from the GDEM dataset of the Computer Network Information Center (Geographic Data Cloud) of the Chinese Academy of Sciences.

\subsection{Methods}

We used 2005 and 2017 land-use classification map as the remote vector data for this study. We selected the data from Anqing City Land Use Master Plan, Anqing City Water Resources Comprehensive Plan, Anqing City Geological Disaster Prevention Plan and then applied it on the platform of ArcGIS followed by calibration and vectorization. The DEM elevation data is a $30 \mathrm{~m}$ resolution grid, derived from the GDEM dataset of the Computer Network Information Center (Geographic Data Cloud) of the Chinese Academy of Sciences.

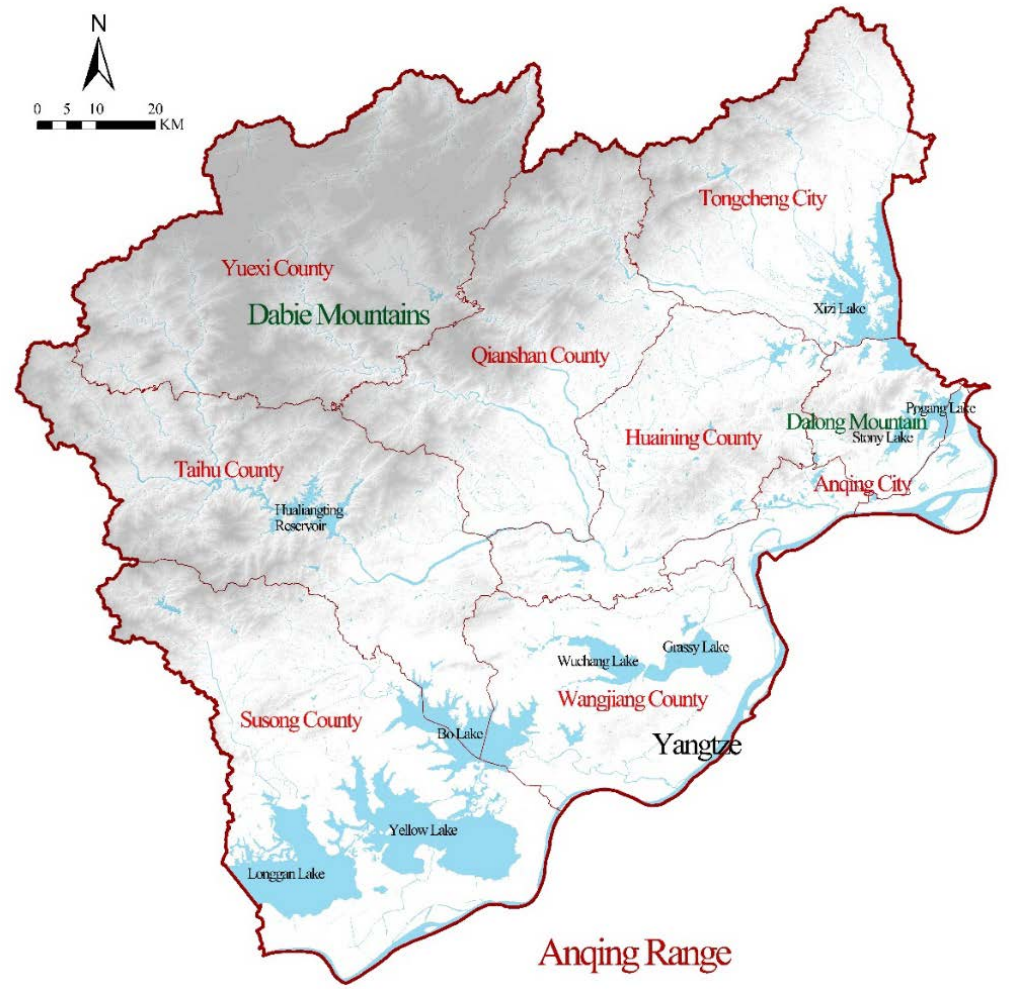

Figure 1. Status map in Anqing City area. 


\section{- Land-use Variables Analysis}

We used constructed 2005 and 2017 land-use data in Anqing that we classified arable land, construction land, waters, woodland, pasture, unused land, garden into two categories of ecological land and non-ecological land. Among them, waters, woodlands, pastures, and gardens belong to ecological land. Arable land, construction land, and unused land belong to other land. We use ArcGIS to superimpose the ecological distribution map in two years. Based on it, the land-use transfer matrix was calculated and we can carry out the qualitative and quantitative analysis combining regional variables graph [6].

\section{- Ecological Security Evaluation Analysis}

The ecological security evaluation analysis can obtain spatial distribution of urban ecological security pattern [7], based on the superposition of ecological disturbance assessment analysis and ecological sensitivity, which refers to the sensitivity of the ecosystem of regional natural and human activities. So we selected 5 main ecological sensitivity factors, including topography, hydrology resources, land-use, ecological resources and natural disasters, combining the regional characteristics of Anqing City. And then we refined the rough factors into 12 detail ecological sensitivity factors and determine the factor weights to carry out single factor evaluation, and comprehensive superposition evaluation to form a spatial distribution of ecological sensitivity. In addition, ecological disturbance refers to the non-continuous events from the outside, blocking the progress of biological systems [8]. So we comprehensively analyzed the main factors of ecological disturbance and 8 interference assessment factors based on human activities in road traffic environment, infrastructure environment and ecological factor environment, combined with local conditions in Anqing City.

- Ecological Security Pattern Construction

Source refers to the landscape type that promotes the development of ecological processes from the perspective of species protection [9]. Source may be composed of areas that need special protection or areas of existing habitat that require representative selection and can fully reflect the requirements of different land-use habitat types. The study considers the source as the core area of ecological protection, just as the core area of ecological security. Therefore, the critical step of pattern construction is to extract contiguous plaques after manual correction, because high safety zones and higher safety zones play a key role in maintaining the health and safety of ecological processes.

To establish a trend to reflect the resistance of ecological land-use, we apply Minimum cumulative resistance model, shorted for MCR, affected by source, distance and landscape interface feature. We use the following formula as modified by $\mathrm{Yu}$ and others:

$$
M C R=f \min \sum_{j=n}^{i=m}(D i j \times R i)
$$

where $f$ is a function of the positive correlation that reflects the relation of the least resistance for any point in space to the distance from any point to any 
source and the characteristics of the landscape base surface; min denotes the minimum value of cumulative resistance produced in different processes of landscape unit i transforming into a different source unit $j$ [8]; $D i j$ is the spatial distance between landscape unit $i$ and source unit $j$; and $R i$ denotes the resistance coefficient that exists in transition from landscape unit $i$ to source unit $j$ [9].

During the MCR calculation, we used the ArcGIS 10.2 software distance analysis module to obtain the minimum cumulative resistance surface of the ecological protection source, based on the resistance coefficient values of different land types in the previous research results (Table 1). The input of the source grid can be a patch or a combination of patches, and the source grid can be connected or unconnected in space.

Based on the MCR model, the cost distance method in ArcGIS 10.2 is used to obtain the components of the ecological security pattern, including strategic nodes, core corridors and potential corridors. The strategic nodes connect the sources and play a critical role in the ecological connectivity of the space network. The core corridor is not only the most important corridor of connecting points, but also the low resistance between the two sources. If the corridor disappears, the most convenient link between points will disappear. The potential corridors are low-resistance valleys, distributed around the source, which has the potential to establish the ecological network connectivity [10].

Comparing the two-year generated secure network, we can conclude 3 types about nodes and corridor, including the core protection, maintenance upgrading, and potential complementary, which will effectively control and guide on land-use in Anqing City.

\section{Result}

\subsection{Ecological Land-Use Variety}

The woodland is mainly distributed in the Dabie Mountain in the northwest and Dalong Mountain in 2005.

The area of woodland in Anqing was mainly distributed in the Dabie Mountains and Dalong Mountain, which accounts for $18.29 \%$ of the total land area of the city in 2017 . The distribution was mainly affected by the project of returning

Table 1. Ecological resistance values for different land types.

\begin{tabular}{cccc}
\hline Land use type & Ecological Resistance & Land-use Type & Ecological resistance \\
\hline Woodland & 1 & Cultivate Land & 100 \\
Rivers, Lakes, Reservoirs & 10 & Garden & 150 \\
Tidal flats, Ditches, Pits & 15 & Village Construction & Land and Other \\
& & Construction Land & 600 \\
Grass & 60 & Urban Construction & 1000 \\
& & Land, Road & \\
\hline
\end{tabular}


farmland to forests. At the same time, some woodland was mainly distributed in the southeastern city, partly converted into construction land.

The distribution of grassland in the downtown area of the west. But based on the conversion for woodland and cultivated land, although a relative low rate, the percentage of grassland in Anqing City was increased at a high speed in 10 years in order to maintain a good urban landscape structure and ecological security. Due to the development of animal husbandry and large-scale farming, grassland began to spread from the western region to the east. Because of the high production, water area also increased significantly in 2017. The extra land mainly came from the cultivated land in the southeast, converted by water land. In 2005, the garden was mainly distributed in the northwest area of the Dabie Mountains. By 2017, suitable area in Anqing City is about $3.42 \mathrm{~km}^{2}$ at a high rate, accounting from the forestry in the northwest region. Viewing Table 2 and Figure 2 for specific quantitative results (Table 2; Figure 2).

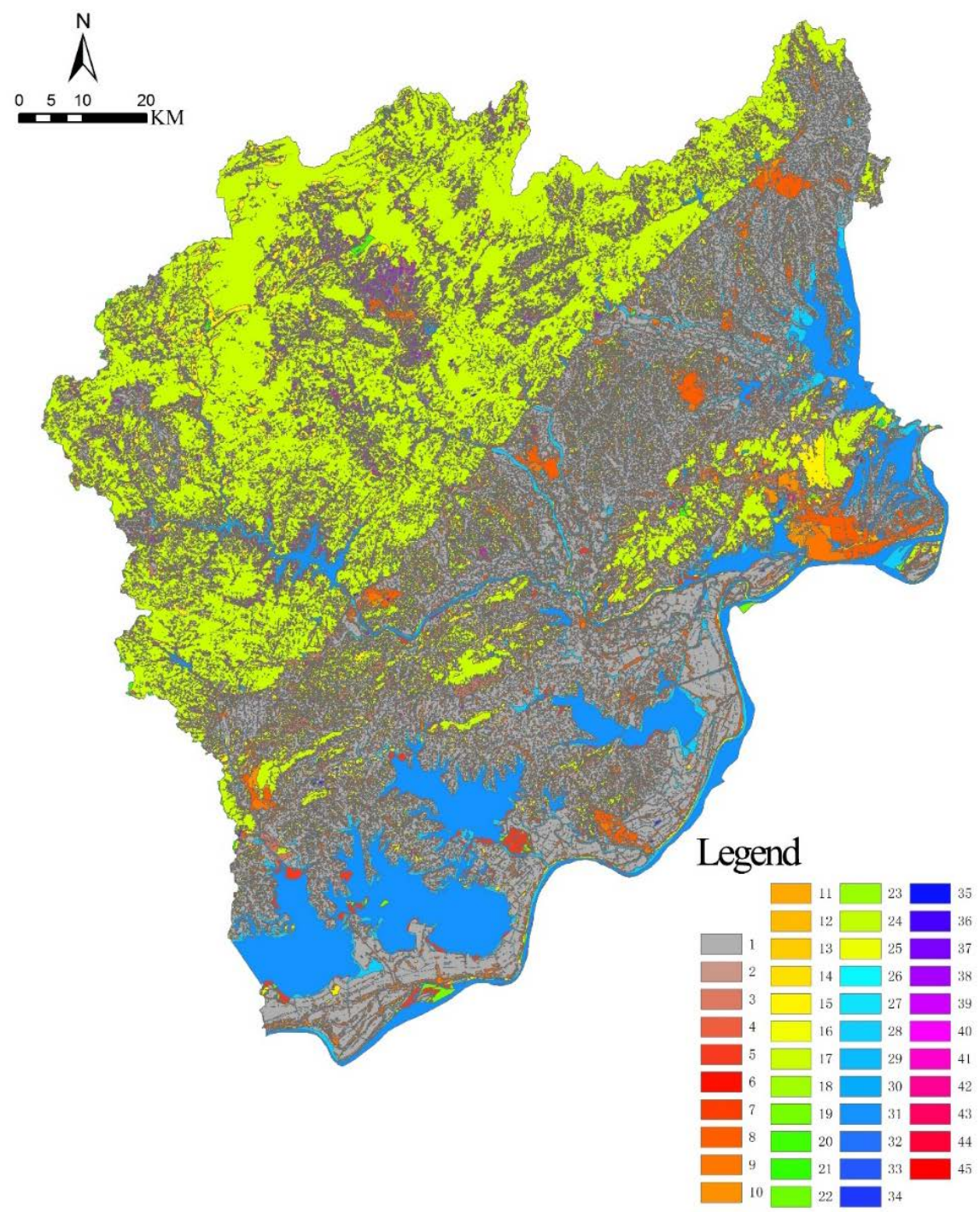

Figure 2. Schematic diagram of land use change in Anqing from 2005 to 2017. 
Table 2. Anqing ecological land transfer matrix from 2005 to 2017.

\begin{tabular}{|c|c|c|c|c|c|c|c|c|}
\hline & $\begin{array}{c}\text { Cultivated } \\
\text { land }\end{array}$ & $\begin{array}{l}\text { Construction } \\
\text { Land }\end{array}$ & Forest & Pasture & Water & $\begin{array}{c}\text { Unused } \\
\text { Land }\end{array}$ & Garden & Total \\
\hline $\begin{array}{l}\text { Cultivated } \\
\text { Land }\end{array}$ & 3282.45 & 947.73 & 1008.42 & 38.10 & 779.51 & 14.67 & 102.44 & 6173.34 \\
\hline $\begin{array}{l}\text { Construction } \\
\text { Land }\end{array}$ & 42.05 & 67.21 & 9.56 & 0.28 & 11.14 & 0.11 & 0.32 & 130.70 \\
\hline Woodland & 716.58 & 283.43 & 4433.88 & 29.42 & 167.41 & 7.21 & 194.49 & 5832.45 \\
\hline Grass & 0.108 & 0.02 & 0.11 & - & - & - & 0.25 & 0.501 \\
\hline Water & 99.26 & 15.43 & 36.71 & 2.75 & 1197.96 & 1.10 & 2.58 & 1355.83 \\
\hline $\begin{array}{l}\text { Unutilized } \\
\text { Land }\end{array}$ & 3.22 & 1.05 & 21.40 & 0.49 & 2.57 & 0.69 & 0.47 & 29.92 \\
\hline Garden & 0.38 & 0.33 & 2.10 & 0.02 & 0.13 & - & 0.44 & 3.41 \\
\hline Total & 4144.07 & 1315.23 & 5512.22 & 71.08 & 2158.75 & 23.80 & 301.01 & $13,539.12$ \\
\hline
\end{tabular}

In Figure 2: Maintaining cultivated land; 2: Construction land-cultivated land; 3: Forest land-cultivated land; 4: Pasture-cultivated land; 5: Water-cultivated land; 6: Unutilized land-cultivated land; 7: Garden-cultivated land; - construction land; 9: maintenance of construction land; 10: forest land - construction land; 11: pasture grass - construction land; 12: water area - construction land; 13: unused land - construction land; 14: garden land - construction land; Cultivated land-forest land; 16: Construction land-forest land; 17: Maintaining forest land; 18: Pasture-forest land; 19: Water area-forest land; 20: Unutilized land-forest land; 21: Garden-forest land; 22: Cultivated land-grazing land; 23: construction land - pasture; 24: woodland - pasture; 25: water - pasture; 26: unused land - pasture; 27: garden - pasture; 28: cultivated land - water; 29: construction land - water ; 30: forest land - waters; 31: water conservation; 32: unused land - waters; 33: gardens - waters; 34: cultivated land - unused land; 35 : construction land - unused land; 36: woodland - unused land 37: Waters - Unutilized land; 38: Maintain unused land; 39: Cultivated land - Garden; 40: Construction land - Garden; 41: Woodland - Garden; 42: Pasture - Garden; 43: Water - Garden ; 44: unused land - garden; 45: keep the garden.

\subsection{Construction of Ecological Security Pattern}

An ecological safety pattern applies the above method of landscape elements, using MCR (the minimum cumulative resistance model method) in 2005 and 2017 (Figure 3). We found that the ecological security pattern of Anqing City is divided into 3 sub-networks, including northwest, southeast and northeast, which have complex and close connection inside the network but fragile link outside the network.

The core corridors with low correlation source were loosely distributed in 2005, at the same time, the northwest Dabie Mountains and northeast Dalong Mountain only extended in potential corridors without tangible corridors. The 


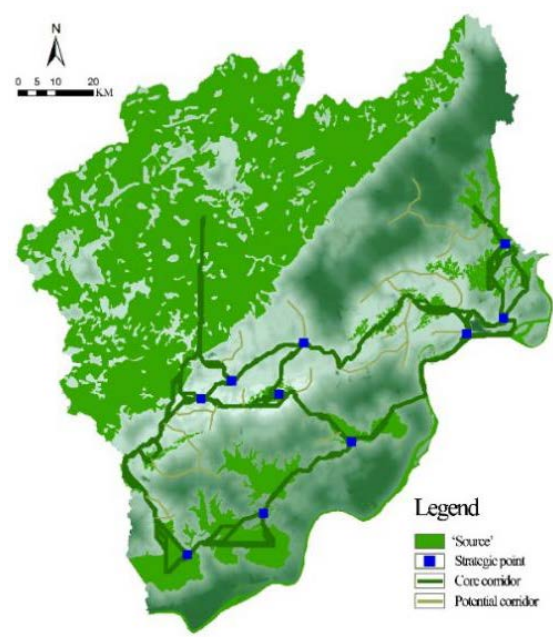

(a)

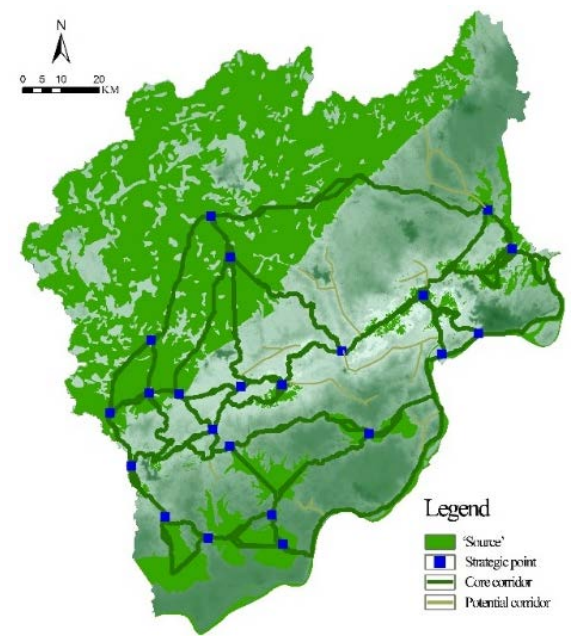

(b)

Figure 3. Anqing security structure chart, (a) in 2005; (b) in 2017.

core corridors were mainly concentrated in the southwest area. In addition, the distribution of corridors was relatively dense with high correlation sources due to the increasing number of points in 2017. The ecological part of other regions was steady increased, which has formed an effective connection in the northeast, except for the northeastern region [11].

\subsection{Ecological Land-Use Impact on Security Pattern}

We superimposed 2005 and 2017 ecological security pattern and found that both the nodes and core corridors were all increased in 3 regions. Two new corridors have been added to the northwest, so the links to the Southwest are closer. Four new strategic nodes are mainly distributed in the area where arable land is converted into forest land. The areas (Dabie Mountains) were regarded the most stable zone in Anqing safety landscape system. The southeast area is the most densely distributed area of strategic points and core corridors. It is also a concentrated area of lakes and rivers. Comparing with the outside critical points and core corridors in the southwest area in 2005, the distribution in 2017 have paid more attention to the internal lakes and rivers network. The reason for the phenomenon is that many arable lands have conserved into forest and water, promoted by the policy of returning farmland to forest and fisher. Therefore, the connectivity and permeability of the ecological security pattern have been greatly enhanced. However, the northeast area with northwest and southeast was a relative fragile area, with fewer critical points and core corridors, especially in the downtown area of Anqing City. That is mainly caused by the conversion of forest and water to construction land. The district has become the most unstable area of ecological security (Figure 4).

\subsection{Guidance of Ecological Security Pattern}

According to the decade trend, we conclude 3 types of critical nodes and 


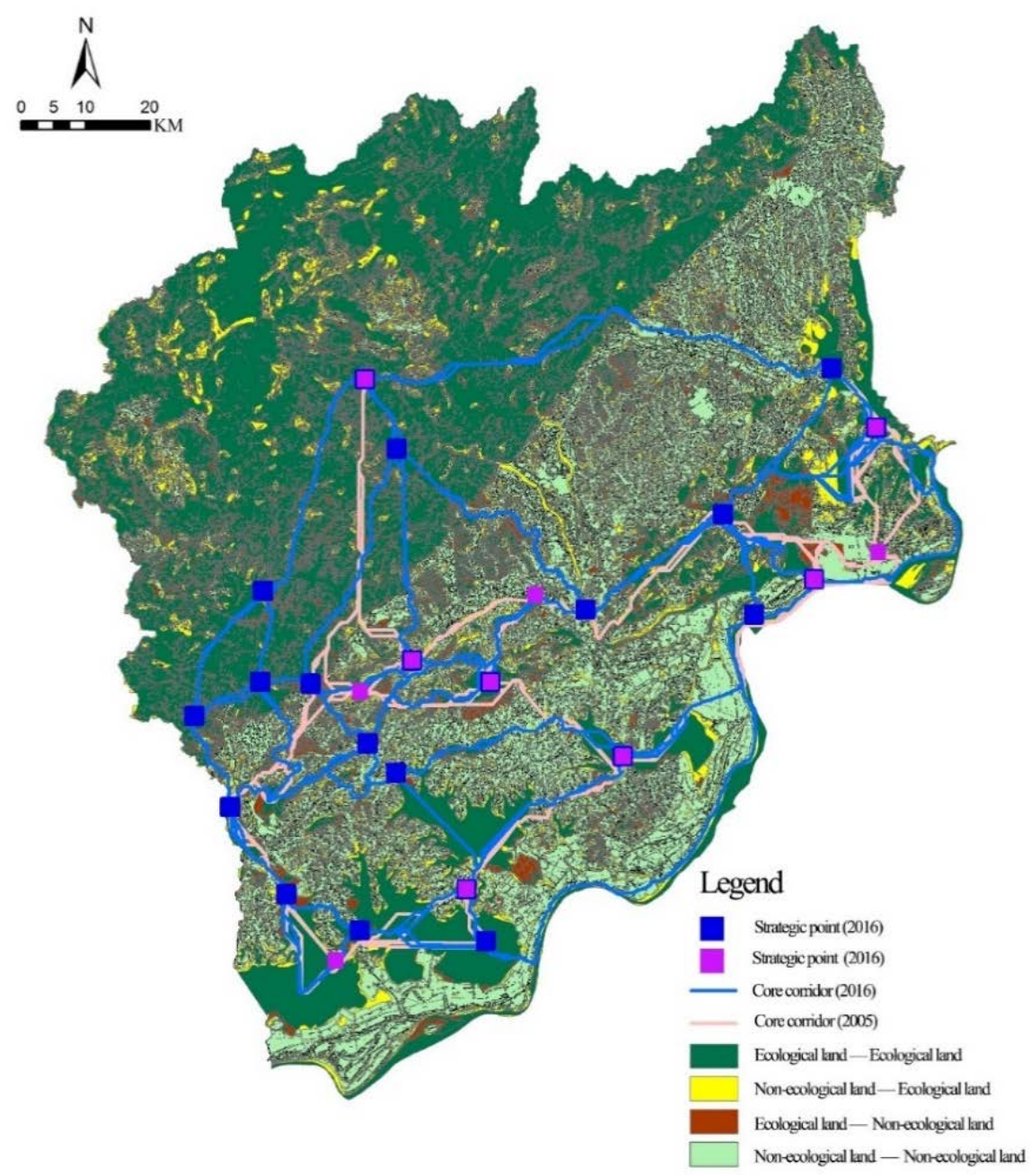

Figure 4. Diagram of ecological land use variety in Anqing from 2005 to 2017.

corridors, including the core protection type, maintenance upgrade type, potential supplementary type, superimposing the ecological land and ecological security pattern in Anqing City. Based on it, it will be the great significance to the ecological security pattern by effective control and guidance (Figure 5) [12].

The core protection type mainly refers to the nodes and corridors that play a prominent role in the whole network [4]. The area most distributed in the critical links of the Dabie Mountains, Longgan Lake, Bohu Lake and the Yangtze River, emphasizing the structural integrity of the plaque according to the principle of no declining ecological functions.

Maintenance upgrade mainly refers to nodes and corridors, threaten by land-use changes. The network is always distributed inside the major ecological nodes, which emphasize ecological maintenance and promote the control and guidance of ecological protection and restoration in ecological improvement.

The potential supplementary type mainly refers to the potential corridor. The network is distributed in the area where the regional connection is blank, which focuses on the continuity of ecological space and the ecological treatment of 


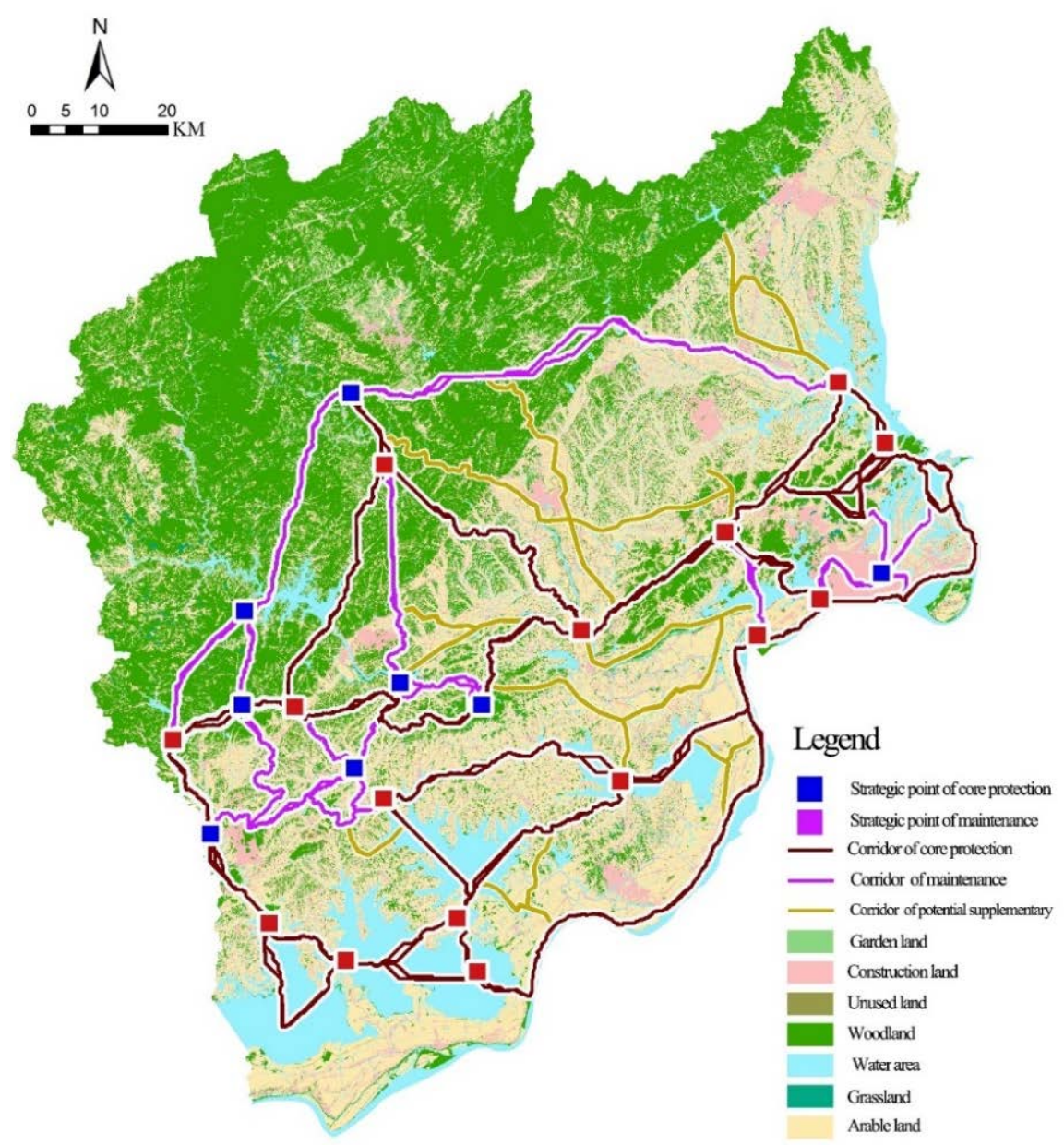

Figure 5. Schematic diagram of control and guidance of ecological security pattern in Anqing in 2017.

related construction. We should follow the principle of both mainly ecological supplement and minor construction, allowing construction activities based on the ecological functions [13].

\section{Conclusions and Discussions}

\subsection{Conclusions}

According to the 2005 and 2017 overlapping analysis of ecological land-use in Anqing City, we inferred the ecological land-use variety in the past two years. Based on ecological sensitivity and ecological interference evaluation analysis, we concluded ecological safety evaluation results as the following.

- Among 4 types of ecological land, grassland, waters and gardens all have increased, with the largest area of water growth. But only the area of forest has decreased from 2005 to 2017.

- There are several land-use about the forest and construction land, conversed by cultivated land. Due to the small base number and conversion, the area always locates in the Dabie Mountain and Fu Mountain, affected by return- 
ing farmland to forest. Based on it, the urban expansion construction land mainly distributed in the downtown in the southeast of Anqing.

- Through ecological safety assessment, the high-security zone is distributed in the northwest forestland, the higher-security zone is distributed in the southwest river and lake. Besides, the low-security zone and the lower-security zone are distributed in the southern Yangtze River plain.

- From 2005 to 2017, the strategic nodes and core corridors in 3 districts all increased. The connection between northwest area and southwest area has become closer. We pay more attention to the network link between southeast area and internal lakes and rivers. The northeast area is affected by the conversion of forest and water to construction land. There are partly declining strategic nodes and cores.

- Through the comparison of the strategic nodes and corridors from 2005 to 2017, we concluded 3 types, including the core protection type, maintenance upgrade type and potential supplementary type. The ecological land in the core protection area emphasizes the structural integrity of the plaque. We should strictly control it according to the principle of no declining the ecological function. Maintaining the ecological land in the enhanced area emphasizes ecological maintenance and promotes the control and guidance of ecological protection and restoration in the ecological improvement area [14]. The principle of ecologically potential supplemented areas is supplementary construction and ecological supplements, allowing construction activities according to the direction of ecological function protection.

\subsection{Discussions}

The ecological security pattern is a network pattern, playing an important role in guarding human life and economic development [15]. For urban land, the protection of ecological land and the expansion of constructed land are co-existent processes. Ecological land refers to the land-use type that mainly provides ecosystem services and usually includes farmland, woodland, and water bodies. The dynamic change in ecological land area is the main driver of changes in urban ecosystem services. Putting forward the concept of suitable ecological land helps in the calculation of the spatial range of ecological land needed to meet the minimum requirements of a healthy urban environment as well as facilitates urban planners to solve the conflicts between urban development and protection of ecological land in order to maintain a stable urban ecosystem. Studies on the ecological land use and ecological security pattern of Anqing in 2005 and 2017 can reflect significant changes in the ecological security pattern in Anqing City, both the strength of the connectivity and balance of ecological security pattern in city area and fragile in downtown area. In the future, the construction of ecological security pattern in Anqing should be combined with urban and rural planning and land-use planning to build the overall ecological security pattern from the perspective of city area. In addition, we should firstly strengthen the control of ecological land management about core protection type, and secondly main- 
tain ecological guidance about enhanced restoration type, and finally preserve spatial continuity and ecological treatment about potential supplemental types.

In addition, it should be noted that there are some defects in this study, for example, when we use the MCRM to select landscape type and construct the ecological land security pattern, a large number of studies have limitations in the choice of single factors. It is critical to consider multi factors, including the social economic level, environmental pollution level and so on. These factors affect the ecological security man-made element. Besides, the control and guidance of ecological security pattern need further design integrating with specific urban and rural planning and land-use policy. The improvement of ecological security requires overall strategic and policy and transformation of land use nature and function, requiring the coordination of ecology and economy. As long as improving the scientific use of land, we can exert greater ecological and economic benefits at the same time.

\section{Conflicts of Interest}

The authors declare no conflicts of interest regarding the publication of this paper.

\section{References}

[1] Kabrick, J.M., Zenner, E.K., Dey, D.C., Gwaze, D. and Jensen, R.G. (2007) Using Ecological Land Types to Examine Landscape-Scale Oak Regeneration Dynamics. Forest Ecology and Management, 255. https://doi.org/10.1016/j.foreco.2007.09.068

[2] Vimal, R., Mathevet, R. and Thompson, J.D. (2012) The Changing Landscape of Ecological Networks. Journal for Nature Conservation, 20.

[3] Ma, K.M., Fu, B.J. and Li, X.Y. (2004) Regional Ecological Security Pattern: Concept and Theoretical Basis. Journal of Ecology, 24, 761-768.

[4] Fu, Q. and Gu, C.L. (2017) Evaluation of Ecological Security Pattern Based on Ecological Network. Chinese Journal of Applied Ecology, 28, 1021-1029.

[5] Chu, J.L., Wang, P., Gu, K.K. and Wang, Y.Z. (2017) The Construction of Ecological Security Pattern and the Development Strategy of Construction Land in Mountain-Type Cities. Acta Ecologica Sinica, 36, 7804-7813.

[6] Lurgi, M. and Robertson, D. (2011) Automated Experimentation in Ecological Networks. Automated Experimentation, 3. https://doi.org/10.1186/1759-4499-3-1

[7] Zhang, W.J. (2007) Computer Inference of Network of Ecological Interactions from Sampling Data. Environmental Monitoring and Assessment, 124.

[8] Liu, B.Y. and Wu, M. (2012) Correlation Analysis of "Network Effectiveness" and Spatial Pattern of Urban Green Space Ecological Network. Chinese Garden, 28, 66-670.

[9] Zhu, M., Xie, G.Z. and Qiu, P.H. (2018) The Change of Ecological Land Use and Safety Pattern in Haikou City. Acta Ecologica Sinica, No. 9, 1-9.

[10] Getz Wayne, M. and Saltz, D. (2008) A Framework for Generating and Analyzing Movement Paths on Ecological Landscapes. Proceedings of the National Academy of Sciences of the United States of America, 105.

https://doi.org/10.1073/pnas.0801732105 
[11] Coşkun, H.C. and Bülent, O.M. (2010) Establishing Ecological Networks for Habitat Conservation in the Case of Çeşme-Urla Peninsula, Turkey. Environmental Monitoring and Assessment, 174. https://doi.org/10.1007/s10661-010-1447-y

[12] Peng, J., Yang, W., Xie, P. and Liu, Y.X. (2017) The Division of Green Space Ecological Network Construction in Guangdong Province Based on Ecosystem Service Supply and Demand. Acta Ecologica Sinica, 37, 4562-4572.

[13] Geng, K., Wang, B.Q. and Shen, Q.J. (2017) Study on the Evaluation Method of Shanghai Ecological Network System. Shanghai Urban Planning, No. 2, 82-89.

[14] Pawłat-Zawrzykraj, A. and Podawca, K. (2016) Implementation of Ecological Network in Existing Conditions of Municipal Spatial Management. Annals of Warsaw University of Life Sciences-SGGW. Land Reclamation, 48.

https://doi.org/10.1515/sggw-2016-0023

[15] Rudolf, V.H.W. and Lafferty, K.D. (2010) Stage Structure Alters How Complexity Affects Stability of Ecological Networks. Ecology Letters, 14.

https://doi.org/10.1111/j.1461-0248.2010.01558.x 